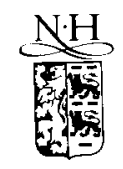

ELSEVIER

\title{
Market liberalization and the psychology of firm performance
}

\author{
Sumit K. Majumdar * \\ School of Business Administration, The University of Michigan, Ann Arbor, MI 48109-1234, USA
}

Received 22 March 1993; revised 15 February 1994

\begin{abstract}
In this paper we study whether the progressive liberalization of the U.S. telecommunications industry has altered the psychology of firms' behavior and led to performance changes. A detailed theoretical framework is developed, based on extension of the postulates of $\mathrm{x}$-efficiency theory. Such an extension of $\mathrm{x}$-efficiency theory enables us to make predictions regarding the direction of performance changes and whether among the various measures of performance there are likely to be cross-sectional differences, even as these different measures change over time. Two performance measures are computed. The first measures the ability of firms to maximize revenues, given their resources; the second measures their ability to reduce costs given the level of outputs generated. We find that market liberalization has significantly impacted the internal psychology within firms, in encouraging both entrepreneurially-oriented and productivity-oriented behavior. However, over time as the market gets more and more liberalized it is the entrepreneurially-oriented behavior that is dominant. We also examine whether ownership differences cause divergences among the firms studied in behavior and performance. We find that erstwhile AT \& T-owned firms are always superior to independents in revenue-maximizing skills, but in an era of monopoly were not cost minimizers. In a liberalized environment their cost minimization skills are also superior to the independent firms.
\end{abstract}

\footnotetext{
*E-mail: sumit.k.majumdar@um.cc.umich.edu; Tel.: +1 313763 4610; Fax: +1 3137635688.
} 


\section{Introduction}

Points of view exist that suggest market liberalization in many industries is impossible, with such premises resting on the belief that there are benefits to horizontal and vertical control of industries. It is assumed that the level of scale and scope economies are such as to preclude competition, since new firm entry will often lead to wasteful resource duplication (Baumol et al., 1982). The above views are driven by technological inter-dependency considerations, but the existence of managerial efficiencies does not necessarily follow as a result (Shepherd, 1983). However, significant technological changes are also occurring in many industrial sectors. The first-order consequences of these are changes in public policy, allowing the liberalization of markets. A second-order psychological effect is the impact such policy changes have at the micro-micro level on firms within the liberalized industry. Increasing liberalization of an industry is a means toward eliminating inefficiencies in general (Comanor and Leibenstein, 1969); it is also a means of stimulating innovativeness and motivating firms to fully exploit economic opportunities that may be present in their economic environments (Leibenstein, 1976).

In this paper we examine whether the increasing liberalization of the U.S. telecommunications industry environment, consequent upon the technological and institutional changes that have taken place, has indeed led firms to improve their micro-micro performance. A powerful set of postulates for explaining such performance changes exists in x-efficiency theory, and we use these postulates in developing a theoretical framework to explain intra-firm psychological changes arising from market liberalization. Such changes lead to subsequent performance changes in firms, and we then illustrate performance changes of individual firms comprising the U.S. telecommunications industry for a fifteen-year period: 1973 to 1987 . This paper is structured as follows. In Section 2 we develop our theoretical framework. In Section 3 we describe the empirical research design; this section includes a discussion of the telecommunications industry and the application of data envelopment analysis (DEA) to measure performance. In Section 4 we analyze the initial results. Section 5 contains an analysis of results by ownership category. The U.S. telecommunications industry is unique in that there have been several private entities which have operated telephone services in the U.S.A, unlike in other countries where one state-owned monopoly has always dominated; interesting psychological 
issues emerge as a result of divergent ownership patterns. Section 6 includes a concluding summary.

\section{The theoretical framework}

\subsection{Introduction}

The fact that a liberal market environment is a spur for firms to be efficient and innovative is very well recognized. Adam Smith (1776/1937) postulated that the superiority of the market as a vehicle for economic coordination reacted largely on its mobilization of incentives; the market tapped the psychology of individual self-interest in a way that no single organization could hope to. Subsequently, Hayek (1945) developed the view that the market, by economizing on information, minimized the enormous costs of collecting and transmitting information that beset a central body planning the operations of a large system.

Nevertheless, these views only reflect the exchange dimension, wherein transformed goods are allocated according to demand by a coordination process, so that value can be determined (McNulty, 1968). Yet there is a second institution, the firm, which, with the aid of resources, determines physical form and the transformation of goods. The mechanisms which induce it to become efficient and innovative are often treated as if they belong in a "black box". Hence, as Leibenstein (1987, p. 62) writes: "nowadays we would see at least one deficiency in the market solution: No connection is made between the ownership of resources and the motivation that would result. In other words, the coordination problem is divorced from the motivation problem."

How can we integrate notions of coordination and motivation so that we fully understand the linkages between exchange and transformation? X-efficiency theory offers us this possibility. The basic notion that underlies traditional, or neo-classical notions of economic behavior is that sub-optimal operations are not possible by firms. X-efficiency theory assumes otherwise. Its originator, Harvey Leibenstein, articulates how because of a lack of incentives or imperfect information arising from being sheltered from competition, there is no presumption that functional units within a firm, to which resources arc allocated, will use the resources at hand most efficiently; the difference between the maximal efficiency and actual efficiency of resource utilization is the degree of $\mathrm{x}$-inefficiency (Leibenstein, 1976). 
X-efficiency theory explicitly counts motivation of individuals as part of the input into productive activity, and such motivation is influenced by the amount of utility obtained from work situations (Dovring, 1979). When there is shelter from competition, pressures on individuals to be cost conscious are not forthcoming; costs, after all, can be passed on to consumers. Concomitantly, the price signals transmitted throughout the process of market-place operations are also lacking; thus, intra-firm signals to be entrepreneurial or pro-active in business generation are also absent. Hence, there is a lack of constraints on the behavior of individuals within the firm to exert themselves to their fullest. A perception that such exertions may lead to greater utilities from the work situation is lacking and results in "an outright lack of cost consciousness by some, and among others who may have a general desire to economize a neglect of the details necessary to minimize costs and maximize productivity" (Babilot et al., 1987, p. 206).

We take the position that $x$-inefficiency in firms arises primarily because of individuals' unwillingness to exert themselves to the fullest and maximize their opportunity sets. Thus, resource utilization within the firm suffers. Some causes of non-maximization have been recently listed by Shen (1991) as distraction, imperfect design and operation of workplaces, low aspiration and bounded rationality. These cause the x-inefficiencies that lead to a reduction in the potential output of firms, which is our unit of analysis. Also, some writing has suggested that on-the-job consumption is an instance of maximizing rational behavior at an individual level, and is "efficient" (Stigler, 1976). We reiterate that our unit of analysis is the firm. Therefore, to the extent that such consumption leads to the diversion of resources away from the firm's output, $x$-inefficiency is manifested at the level of the firm. Nevertheless, even such individual consumption may not be optimally undertaken for the reasons Shen (1991) posits. Because firms are not homogenous entities, but possess idiosyncratic and heterogeneous resources, skills and capabilities (Nelson, 1991), the way these resources are configured into packages of unique skills and capabilities also differ. Hence, there can be significant variations within firms in their levels of $\mathrm{x}$-inefficiencies.

\subsection{Behavioral issues}

How does the psychological model operate? The key variables in the theory are pressure and effort, and three aspects of pressure exist. First, 
there is the external pressure in the environment including the market. Second, there is internal pressure as translated from the outside to the inside of the firm. Third, there is the internal response to translated pressure, which is effort oriented towards various dimensions of performance. For example, managers may perceive that new product introductions have to be made in an environment where customers have greater choices; such product-introduction pressures are translated into specific work practice changes, such as structural reorganization, within the firm. To these pressures from management, who are often themselves reacting to endogenous forces, individuals can react in various ways. First, there can be efforts to assume more on-job responsibilities, if past unwillingness to do so or rigidities in job assignments have existed; second, there can be intra-firm entrepreneurial or business development activities undertaken to create new repertoires of activities for the organization.

The key variable is effort, and internal pressures determine intra-firm effort levels of two kinds. The first is discretionary effort, positive in nature, to be innovative and not procedure bound, or "work according to rule". Such effort may depend on the achievement motivations, as described by McClelland and Winter (1969), of individuals who may take a stronger than average interest in revenue-cost relationships when they discern economic opportunities that are emergent. Since effort is a function of human will, the lack of opportunities in the economic environment acts as a brake on the natural propensities of human beings to better their lot, and thus build up human capital. Such abilities lie latent, with a consequent impact on intra-firm performance, because of the lack of possible rewards.

The second type is effort to reduce inertial behavior which may be engendering sub-optimal decisions. Inertia is a ubiquitous human and social phenomenon; boundaries of the cognitive range of individuals exist, within which intra-firm and external signals are read, yet no behavioral changes may occur as a result because of the forces of inertia (Tanner and Swets, 1954). Such forces of inertia, and the width of these cognitive boundaries, determine behavior and thus changes in overall performance of the firm. When boundaries within which inertia exists get narrower and more compressed as a result of internal pressures, then rapid changes in such performance may be expected as a result of efforts to reduce inertia. Effort, therefore, is of two kinds within the constructs of x-efficiency theory, and each has a role in determining overall performance.

Competition, arising from the market liberalization, enables market 
differentiation to occur where premium prices may be sustainable. At a macro or aggregative level the presence of more firms can generate supply of goods greater than in a monopoly regime. Such supply factors also generate demand which is qualitatively and quantitatively superior to demand patterns seen in a monopoly regime. Given the increasing pool of information that develops as a result of competition intensification (McCain, 1975), an internal market for ideas to undertake new activities, so as to fill niches and recover premium prices, can develop within the firm and be used to create motivational incentives. Such motivational incentives, and the availability of opportunities, spur the supply of effort towards entrepreneurial acts, as firm members see themselves performing tasks not done by others. Resulting from the release of latent entrepreneurial spirits, rising individual effort is expended towards creating new revenue streams, so that employees can also then share in the gains brought about by external market shifts (Leibenstein, 1987). Hence, a firm-level phenomenon that we predict will happen is an increase in its ability to generate revenues.

Emerging pressures from a liberalized and competitive environment create price pressures, and to remain profitable when prices start declining costs have to reduce. According to Leibenstein (1976, p. 207): "The quest for such lower costs transmits itself to individuals, at various levels within the firm, whose sense of success requires that the firm stays profitable or at least solvent, and of whom it is believed, or who themselves believe, that they can influence costs." Since operational employees make up the largest proportion of employees in any firm, such signals have wide diffusion and impact; thus another result of the process of firm-level behavioral changes that we predict is an improving trend in resource utilization and cost minimization, as the environment becomes more competitive.

Based on ideas from X-efficiency theory, Hoenack (1989) posits another argument. Firm-level reward systems are often geared towards those who help enhance revenues, rather than towards those who save costs. Thus, greater personal rewards often accrue if one contributes to the increased revenues of a firm, and individual and group efforts are likely to be directed towards activities which create personal revenue-oriented "rent" streams. Arising from increasing opportunities, most intra-firm visibility can thus be acquired through entreprencurial and revenuc-enhancing actions; hence individual predilections converge toward creating revenue streams and a prediction from the theoretical framework is that firms will be relatively more $\mathrm{x}$-efficient in their ability to maximize revenues relative 
to their ability to minimize costs. While firms may be relatively more $\mathrm{x}$-efficient in maximizing revenues relative to minimizing costs, because reward systems constrain cost-efficiency seeking behavior, nevertheless, the absolute quantum of both revenue maximization and cost minimization $\mathrm{x}$-efficiencies increase, as liberalization provides market opportunities, and pressures to perform efficiently develop.

\section{Empirical study}

\subsection{The telecommunications industry: Description and choice of sector}

We evaluate the dynamics of $x$-efficiency arising out of market liberalization in a major sector of the U.S. telecommunications industry. While AT \& T was the dominant monopoly supplier, it was comprised of 22 separate, semi-independent, operating companies which since the 1984 divestiture have become part of seven regional holding companies (RHCs). Other operating companies include those belonging to several diverse groups such as GTE, United, Continental and Central telephone systems, as well as Bell-related independents such as Cincinnati Bell, Rochester Telephone and Southern New England Telephone. These non-Bell (nonRHC after 1984) companies provide telephone services over 60 percent of the land area of the United States. While they have not enjoyed near-equal monopoly status as many of the AT\&T companies did, they have been suppliers of services in many cities such as Cincinnati and Rochester, and have been the key supplier in much of rural or suburban U.S.A. Together these operating firms account for over two-thirds of all telephone activities in the United States, and their total revenue estimates for 1987 were at least $\$ 70$ billion.

Studies (Langdale, 1983; Meyer et al., 1980) show that business customers, while accounting for a relatively low proportion among total customer numbers, account for the most significant revenue components of operating companies. These customers are also the ones most susceptible to bypass. Bypass, defined by Weisman (1988) as a direct connection between a customer's premises and another carrier (service bypass) or a self-contained system that avoids services provided by any carrier (facility bypass), is the most direct competitive threat to operating companies. Where the costs of the bypass supplier are lower than those of operating companies, then bypass is economically justifiable and operating companies will be forced to be more efficient to compete. Since the late 1970s technology and institutional frameworks have permitted bypass of local 
operating company systems to occur steadily (Bolter et al., 1990). Simultaneously, these conditions allow scope to existing operating companies to be innovative, and enhance their revenue streams, because greater technology and market choices are available.

Given the preceding industry scenario, we evaluate the performance of the 40 key operating firms, of which 22 (or 55 percent) are the erstwhile AT \& T Bell Operating Companies (BOCs) and 18 (or 45 percent) are other independent companies, in the U.S. telecommunications industry. This is almost the entire population of the key firms making up the industry sector. Possession of empirically-derived data on these two groups of firms will also provide evidence on whether indeed ownership factors are material in $\mathrm{x}$-inefficiency generation. Ownership differences are a key explanator in $\mathrm{x}$-efficiency theory (Shelton, 1967). Within this population there are two groups of firms: AT\& T (RHC) and non-AT\& T (RHC) firms, or the independents, and each group is likely to possess distinctly different behavioral norms arising from the way industry structure evolved in the early 20 th century.

We evaluate changes in x-efficiencies for five time-periods: 1973, 1978, 1981, 1984, and 1987. 1973 is chosen as the starting point because till then there was no effective competition in the industry. "Events" were occurring around then, and by 1978 their lagged impact would be felt. Between 1978 and 1981 technology-driven product-competition evolved faster than anytime ever. No significant deregulatory moves such as the divestiture took place. However, two significant events that occurred were the 1978 Executive decision which allowed price competition to enter into long-distance markets, and the 1981 Computer Inquiry I decision which allowed existing firms to provide value-added network services as a competitive response to other smaller players who could do so. The period 1981 to 1984 was one of transition. With the recognition of technological convergence in the industry, the critical competition-enhancing public policy events were taking place, and changes in the industry market structure were expected to have a significant impact on firm-level outcomes. The last phase, 1984 to 1987, was one of consolidation. After the turbulence of the late 1970s and the early 1980s, the environment was such that competition was conceptualized as the norm, rather than the exception.

\subsection{The data envelopment analysis (DEA) models estimated}

In this sub-section we describe the technique that we use to measure whether the relative ability of operating companies in the telecommunica- 
tions industry to generate more revenues with the resources at hand, or minimize costs given output levels attained, is increasing or not. Such an approach is predicated by the fact that in the theory of the firm a transformation function describes a firm's underlying operations, where maximum output for given levels of other outputs and inputs, or the minimum input required for producing given outputs, with other inputs also given, can be specified. Correspondingly, other functions are: a cost function describing the minimum cost of producing certain outputs, with given inputs, prices and technology; a revenue function describing the maximum revenue obtainable given inputs, outputs, prices and technology; and a profit function describing the maximum profit with given output and input prices and technology.

A common characteristic of each function described above is optimality, whereby a maximum or minimum value achievable, given prices and/or technology, is calculated and each function defines a frontier. The use of frontier models is very relevant. First, the notion of a frontier defines what performance level can be feasibly obtained by firms. Second, deviations from a frontier can be naturally interpreted as a manifestation of $\mathrm{x}$-inefficiency. Third, information about the frontier, and the distance of each firm from the frontier, yields significant policy insights as to what is the rate and direction of change in firm x-efficiency. See Button and WeymanJones (1992), Leibenstein and Maital (1992) and Majumdar (1994) for applications of DEA in the measurement of $x$-inefficiencies.

We use a non-parametric approach, called data envelopment analysis (DEA), to construct frontiers and calculate the associated performance indices of 40 operating firms in the U.S. telecommunications industry for five time-periods: 1973, 1978, 1981, 1984, and 1987. As developed by Charnes, Cooper and Rhodes [CCR] (1978), a generalized multiple output-input measure of performance is developed by means of the following fractional mathematical program, where the ratio of the weighted outputs to weighted inputs for each firm being evaluated is maximized, subject to the constraint that this ratio is less than or equal to the performance of all other observations in the data set and the maximum performance score can be 1 . The general form of the program is:

$$
\text { Objective: } \operatorname{Max} h_{0}=\frac{\sum_{r=1}^{s} U_{r} Y_{r 0}}{\sum_{i=1}^{m} V_{i} X_{i 0}} \text {, }
$$


subject to the constraints:

(a) Less than unity:

$$
\frac{\sum_{r=1}^{s} U_{r} Y_{r j}}{\sum_{i=1}^{m} V_{i} X_{i j}} \leq 1, \quad(j=1,2, \ldots, 0, \ldots, N) .
$$

(b) Positivity:

$$
\begin{aligned}
& U_{r}>0, \quad(r=1, \ldots, s) \\
& V_{i}>0, \quad(i=1, \ldots, m) .
\end{aligned}
$$

The data used for each firm $j_{0}(j=1,2, \ldots, 0, \ldots, 200)$ are the $Y_{r j}$ outputs and $X_{i j}$ inputs and the $U_{r}$ and $V_{i}$ weights are determined objectively from the data. The DEA algorithm calculates an ex-post evaluation of how efficient each firm was with regard to either output maximization or input minimization without making any assumption about either technology or functional form. Optimization is performed $N$ times, computing an optimal set of weights $U_{r}^{*}, V_{i}^{*}>0$ and efficiency measures $h_{0}^{*}$ for each 0 th firm-level observation. The weights are calculated as values to be assigned to each input and output in order to maximize the efficiency score for each firm, and, therefore, can vary from firm to firm.

DEA can be viewed as an extension of simple ratio analysis. With a single output and input, the objective function becomes maximization of a single ratio. The reference set is the observation(s) that is maximum on that ratio. Efficiency for other observations are calculated by comparing the ratio of each observation against the maximum. DEA can also be viewed as an extension of total factor productivity constructs. If each unit were allowed to select the set of weights, in a total factor productivity computation these would be prices; DEA empirically generates weights for each firm for its outputs and inputs which help to present that unit in the best possible light. This is subject to the condition that the set of weights selected does not give any observation an efficiency score of greater than unity. An observation that is superior to all others on any single ratio will be rated efficient. It will have a score of 1 on a scale of 0 to 1 . By assigning high weights to the appropriate variables and very low weights to the other variables, the procedure emphasizes the ratio of one particular output-input, among the several other output-input ratios which can be put into a DEA model, on which this efficient observation excels. 
The CCR approach assumes constant returns to scale. Banker, Charnes and Cooper [BCC] (1984) also show that overall efficiency can be broken up into its technical and scale components, and we use the BCC approach which computes the technical efficiency of each observation, given its scale of operations, for our empirical analysis, whereby we are able to isolate the actual organizational efficiency. To solve the non-linear, non-convex fractional program denoted in (1), either of two linear programs can be formulated. The first one constrains the weighted sum of inputs to unity and maximizes the outputs to be attained. This is the output-augmentation model and we use such a formulation to calculate the revenue maximizing frontier for the 200 firm-level observations in our data set. The objective function is to maximize output given the quantities of various inputs to hand. If an observation is inefficient, then the procedure identifies how much quantities of each output can be proportionally expanded by that firm so as to be similar to similar efficient firms using similar quantities of inputs. (Recollect that we have five time-windows over which we evaluate the performance of 40 firms.) This formulation yields performance scores for each firm relative to its own performance over time, and to the performance of other firms in the same and other time periods. We call this score the revenue maximization score. The following are used as outputs and inputs. For the first formulation, which we call for convenience the revenue maximization score (REV MAX), we use three outputs $(r=3)$, which are (1) total local revenues, (2) total toll revenues, and (3) total access and other revenues, and three inputs $(s=3)$, which are (1) total number of switches, (2) the total number of access lines, and (3) the total number of employees. The revenue figures are deflated to 1973 using the consumer price index for telephone services obtained from the Statistical Abstract of the United States published by the Bureau of the Census. Data on the various outputs and inputs are obtained from the annual Federal Communications Commission publication titled Statistics of Communications Common Carriers.

A second formulation can then be written, which constrains the sum of the weighted outputs at unity and minimizes the inputs needed. This is called the input conservation formulation. We use such a formulation to calculate a cost minimizing frontier for the firms and call the results obtained the cost minimizing score (COST MIN) for the firms. The outputs $(r=2)$, used for each firm are: (1) total number of local calls, and (2) total number of toll calls; the inputs $(s=3)$ used are: (1) maintenance and depreciation expenses, (2) traffic, commercial and general office expenses, 
and (3) other expenses. Maintenance and depreciation expenses are deflated using the producer price index for capital equipment and traffic, commercial, general office and other expenses are deflated using the producer price index for intermediate goods, both obtained from the Statistical Abstract. While the total number of toll and local calls is very highly correlated with minutes of toll and local usage, the unavailability of minutes data prior to 1980 precluded their usage as output variables.

DEA is a methodology directed to frontiers rather than to central tendencies and it is particularly useful in uncovering relationships not uncovered by other methods of estimation (Seiford and Thrall, 1990). The advantage of the DEA lies in its approach. DEA optimizes for each individual firm, in place of overall aggregates and the single optimization normally performed in statistical regressions. Instead of trying to fit a regression plane through the center of the data, DEA floats a piece-wise linear surface to rest on top of observations, and it is driven by the data rather than by restrictive assumptions as to the nature of the technology or functional form.

We have highlighted that these are the major models, and different results can be obtained from different models. The CCR model assumes constant returns to scale while the $\mathrm{BCC}$ model assumes variable returns to scale. In other words, the BCC model calculates a technical efficiency score at the given scale of operations. Whether returns to scale characteristics display increasing, constant or decreasing patterns is a subsequent issue, and the BCC model isolates pure technical efficiency from the confounding effects of scale efficiency, while the CCR model yields a score of total efficiency which is a composite of technical and scale efficiency. Within the BCC and CCR models there can be an output-augmentation orientation or an input-conservation orientation. These orientations capture different facets of behavioral and psychological objectives present within firms.

\section{Analysis of results}

While individual scores capturing the revenue maximization and cost minimization abilities of each firm have been calculated, discussion of the theoretical implication of the results are based on the average values of these scores for the 40 firms in the sample, by each time-period, and then the pattern of scores of the Bell (ex-Bell from 1984 and belonging to the various RHC's thereafter) versus the non-Bell operating companies are 
Table 1

Descriptive statistics for revenue maximization score

\begin{tabular}{lllllc}
\hline & \multicolumn{5}{l}{ Years } \\
\cline { 2 - 6 } & 1973 & 1978 & 1981 & 1984 & 1987 \\
\hline Mean (all companies, $N=40)$ & 0.5584 & 0.7583 & 0.9118 & 0.9006 & 0.9141 \\
Median & 0.5225 & 0.7749 & 0.9547 & 0.9359 & 0.9519 \\
Mean (Bell Companies, $N=22$ ) & 0.5843 & 0.7841 & 0.9371 & 0.8762 & 0.9435 \\
Mean (non-Bell Companies, $N=18$ ) & 0.5708 & 0.7268 & 0.8811 & 0.9303 & 0.8782 \\
Standard deviation & 0.1491 & 0.1023 & 0.1028 & 0.1004 & 0.0941 \\
Minimum score & 0.3844 & 0.5720 & 0.6047 & 0.6438 & 0.7065 \\
Maximum score & 1.0000 & 1.0000 & 1.0000 & 1.0000 & 1.0000 \\
\# of frontier defining firms & 3 & 1 & 10 & 14 & 16 \\
\# of frontier defining firms to total & $7.5 \%$ & $2.5 \%$ & $25 \%$ & $35 \%$ & $40 \%$ \\
\hline
\end{tabular}

compared. Descriptive statistics of the two sets of scores are given in Tables 1 and 2.

We undertake a detailed analysis of the trends in the two different measures of revenue maximization that we have computed. From reviewing Table 1 we note that the rise in the revenue maximization score, from 0.5584 in 1973 to 0.9141 in 1987 is significant. Recollect that a score of 1 denotes a firm's ability to extract maximum possible outputs, given inputs. That the average score for 1987 is greater than 0.9 shows that firms are able to extract a very large proportion of obtainable revenues with their given resources, relative to 1973 when the average scores were around the 0.5 mark. The industry sector as a whole may not be behaving optimally in realizing all potential revenues with assets, but psychological changes within firms seem apparent as it has certainly moved towards that optimum.

Table 2 gives a breakdown of the Wilcoxon (1945) test results carried out on the REV MAX score, as it is compared from one period to the next.

Statistically, the REV MAX score for 1973 and 1978 are significantly lower than those for the succeeding periods (all $p$ values are $<0.0001$ ). However, the scores for 1981, 1984 and 1987 are very similar, and are not statistically different from one another. This indicates that between the periods 1973 to 1978 , and from 1978 to 1981, firms were striving hard to reach the optimal frontier that would define their revenue maximization ability. However, by 1981 they were very near that frontier, and while further improvements toward an optimum score would be statistically significant, it seems that there has been a peaking. Also of interest is that 
Table 2

Wilcoxon test statistics and results: Pair-wise comparison of mean revenue maximization score between years $^{\mathbf{a}}$

\begin{tabular}{lccccl}
\hline Years & 1978 & 1981 & 1984 & 1987 & Items \\
\hline 1973 & 5.219 & 5.359 & 5.359 & 5.373 & Test statistic \\
& $<0.0001$ & $<0.0001$ & $<0.0001$ & $<0.0001$ & $p$ value \\
1978 & 5.442 & 5.121 & 5.390 & Test statistic \\
& & $<0.0001$ & $<0.0001$ & $p$ value \\
1981 & & -0.992 & -0.598 & Test statistic \\
& & 0.3214 & 0.5496 & $p$ value \\
1984 & & & 0.654 & Test statistic \\
& & & 0.5128 & $p$ value
\end{tabular}

${ }^{a}$ The test carried out is to evaluate the hypothesis that the score for the year in the row is less than the score for the year in the column.

there has been a slight but non-significant decline in the score between 1981 and 1984, but there was an improvement between 1984 and 1987.

Table 3 reveals that the average cost minimization score has risen steadily between 1973 and 1987 .

From Table 3 it is observed that the average cost minimization scores for the firms range from 0.6644 in 1973 to 0.8678 in 1987 , and the rise is steady and monotonic. This indicates that while firms are not at an optimal position with respect to producing outputs with the technically lowest feasible costs, they are clearly increasing their $\mathrm{x}$-efficiencies in minimizing levels of costs and improving the utilization of their operating resources. A statistical comparison of the average cost minimization scores between years follows in Table 4.

Table 3

Descriptive statistics for the cost minimization score

\begin{tabular}{llllll}
\hline & \multicolumn{7}{l}{ Years } & & & \\
\cline { 2 - 6 } & 1973 & 1978 & 1981 & 1984 & 1987 \\
\hline Mean score & 0.6644 & 0.7488 & 0.7654 & 0.8237 & 0.8678 \\
Median score & 0.6175 & 0.7293 & 0.7789 & 0.8494 & 0.8873 \\
Mean (Bell companies) & 0.5813 & 0.6992 & 0.7194 & 0.8759 & 0.8733 \\
Mean (non-Bell companies) & 0.7658 & 0.8096 & 0.8210 & 0.7599 & 0.8610 \\
Standard deviation & 0.1702 & 0.1299 & 0.1189 & 0.1409 & 0.1315 \\
Minimum score & 0.4505 & 0.5099 & 0.4432 & 0.5124 & 0.5755 \\
Maximum score & 1.0000 & 1.0000 & 1.0000 & 1.0000 & 1.0000 \\
\# of frontier defining firms & 3 & $\mathbf{3}$ & 3 & 5 & 10 \\
\% of frontier firms to total & $7.5 \%$ & $7.5 \%$ & $7.5 \%$ & $12.5 \%$ & $25 \%$ \\
\hline
\end{tabular}


Table 4

Wilcoxon test statistics and results: Pair-wise comparison of mean cost minimization scores between years $^{\text {a }}$

\begin{tabular}{lccccl}
\hline Years & 1978 & 1981 & 1984 & 1987 & Items \\
\hline 1973 & 4.300 & 4.082 & 3.844 & 4.591 & Test statistic \\
& $<0.0001$ & $<0.0001$ & $<0.0001$ & $<0.0001$ & $p$ value \\
1978 & & 2.371 & 0.903 & 4.271 & Test statistic \\
& & 0.0177 & 0.0037 & $<0.0001$ & $p$ value \\
1981 & & 2.608 & 4.256 & Test statistic \\
& & 0.0091 & $<0.0001$ & $p$ value \\
1984 & & & 2.038 & Test statistic \\
& & & & 0.0416 & $p$ value
\end{tabular}

${ }^{a}$ The test carried out is to evaluate the hypothesis that the score for the year in the row is less than the score for the year in the column.

The monotonically rising trend in cost minimization between the periods 1973, 1978, 1981, 1984 and 1987 is also statistically validated. From Table 4 we note that the scores for each period are significantly lower (all $p$ values are $<0.05)$ than those for the succeeding periods. However, unlike in the case of the revenue maximization score, closeness to an optimal score is not reached in 1987, let alone in 1981. Hence, there is potential for future productivity gains, as competition intensifies and firms have no recourse but to increase cost-efficiency scores in order to sustain themselves against falling profits. Nevertheless, the fact that the firms are continuously striving to move towards an optimum, and be efficient in resource utilization, is further borne out when we read Table 4 across the diagonal; from Table 4 it is seen that increases in the average score between all pairs of periods ( 1973 to $1978 ; 1978$ to $1981 ; 1981$ to 1984 ; and 1984 to 1987 ) are significant (all with $p$ values $<0.05$ ), albeit some pairs of years more so than others.

We have postulated earlier as to why we expect revenue maximization scores to differ significantly from cost minimization scores in each period. While the theoretical framework articulates the view that with the onset of a competitive environment, both the revenue maximization and cost minimization abilities will increase equally as the complex motivational schema within firms are altered, often the existing reward systems within firms motivate more revenue-enhancing rather than cost-cutting behavior. We do find distinct patterns of differences between the averages of both the revenue maximizing and the cost minimizing scores; thus our rationale seems justified by the evidence to hand. These results are given in Table 5, which contains a year-by-year comparison of the revenue maximization score (REV MAX) and the cost minimization score (COST MIN). 
Table 5

Wilcoxon test statistics and results: Test of differences between the revenue maximization score and the cost minimization score for different years ${ }^{\text {a }}$

\begin{tabular}{lllrr}
\hline Year & $\begin{array}{l}\text { Mean revenue } \\
\text { maximization } \\
\text { score }\end{array}$ & $\begin{array}{l}\text { Mean cost } \\
\text { minimization } \\
\text { score }\end{array}$ & $\begin{array}{l}\text { Test } \\
\text { statistic }\end{array}$ & $p$ value \\
\hline 1973 & 0.5584 & 0.6644 & -2.819 & 0.0048 \\
1978 & 0.7583 & 0.7488 & 0.538 & 0.5908 \\
1981 & 0.9118 & 0.7654 & 3.983 & $<0.0001$ \\
1984 & 0.9006 & 0.8237 & 2.139 & 0.0324 \\
1987 & 0.9141 & 0.8678 & 1.380 & 0.1675
\end{tabular}

${ }^{a}$ The test evaluates the hypothesis that the mean revenue maximization score is greater than the mean cost minimization score for each year.

From Table 5 we note that the average revenue maximization score for 1973 is significantly lower than the cost minimization score $(p<0.05)$. However, as firms place more emphasis on augmenting their revenue generating capabilities such a pattern alters. By 1981 the average revenue maximization score has become significantly greater than the average cost minimization score. Such a trend continues for 1984 as well, but by 1987 the revenue maximization score has already reached a plateau, and the increase in the cost minimization score by that period means that the differences in scores in 1987 are not as large. However, we stress that our evidence is only indirect and the issue is empirical. More micro-evidence as to whether the reward structures of firms either encourage revenue-enhancing or cost-minimizing behavior is warranted. It is also feasible that internal rent-seeking creates $x$-inefficiencies at the level of the firm. Nevertheless, there can be a difference between personal rent-seeking which leads to $\mathrm{x}$-inefficiency, and revenue-maximizing behavior which leads to maximizing one's own visibility along with firm performance. As long as personal behavior does not lead to a diversion of resources away from firm-level activities, that is individual behavior is goal congruent with that of the firm, firm-level performance outcomes will be maximized.

\section{Comparison of performance arising from differences in ownership struc- tures}

So far our discussion has been focused on the average performance of the 40 key firms that make up the industry. However, one advantage of the 
Table 6

Mann-Whitney test results of whether the various performance scores are greater for the Bell companies than for the non-Bell companies in each time period

\begin{tabular}{|c|c|c|c|c|c|}
\hline & \multicolumn{5}{|c|}{ Time periods } \\
\hline & 1973 & 1978 & 1981 & 1984 & 1987 \\
\hline \multicolumn{6}{|c|}{ Revenue maximization score } \\
\hline \multicolumn{6}{|l|}{ Mean: } \\
\hline Bell companies & 0.5483 & 0.7841 & 0.9371 & 0.8762 & 0.9435 \\
\hline Non-Bell companies & 0.5708 & 0.7268 & 0.8811 & 0.9303 & 0.8782 \\
\hline Test statistic & 0.7476 & 2.1749 & 2.0798 & -1.6719 & 1.9303 \\
\hline$p$ value & 0.5457 & 0.0296 & 0.0375 & 0.0945 & 0.0536 \\
\hline \multicolumn{6}{|l|}{ Cost minimization score } \\
\hline \multicolumn{6}{|l|}{ Mean: } \\
\hline Bell companies & 0.5813 & 0.6992 & 0.7194 & 0.8759 & 0.8733 \\
\hline Non-Bell companies & 0.7658 & 0.8096 & 0.8210 & 0.7599 & 0.8610 \\
\hline Test statistic & -3.0449 & -2.4059 & -2.6780 & 2.3244 & 0.1359 \\
\hline$p$ value & 0.0023 & 0.0160 & 0.0074 & 0.0201 & 0.8919 \\
\hline
\end{tabular}

DEA method is that we can obtain scores for individual firms and for groups of firms. This makes micro-micro comparison much easier. Ownership patterns significantly impact on firm-level behavior and performance, since the nature of incentive systems in place may differ widely. Also, in Tables 1 and 3 the means of the various scores are computed for the whole sample, and separately for the Bell and non-Bell sub-groups. Recollect that in our panel of firms 22 of the firms were, prior to the 1984 divestiture, part of the AT \& T family. Since 1984 they are part of the families of the seven regional holding companies. For convenience we refer to these firms as Bell companies for all the time-periods. There are 18 other independent companies in our sample. These have not been as much in the limelight as the Bell companies. However, they are not an insubstantial part of the industry mosaic. Table 6 gives the results of the Mann-Whitney (1947) test of the hypothesis that the means of each of the performance scores, for each period, is greater for the Bell companies than for the non-Bell operating companies.

The test we undertake is predicated by the notion that ownership differences can also cause significant variations in performance. In fact, the earliest empirical study on x-efficiency by Shelton (1967) established precisely the fact that differential incentives altered the psychological make-up of employees in franchised versus managed organizations. In the U.S. telecommunications industry, the Bell operating companies belonged to 
AT \& T. AT \& T became a dominant monopoly in the late nineteenth and early twentieth centuries to exploit networking economies and provide universal service. Given legal monopoly rights, a significant part of its business risk was eliminated. Consequently, the environment AT \& T and its constituent firms operated in was secure. While it provided services over only 40 percent of the U.S. land area, these were the most lucrative territories. Other independent firms operated in 60 percent of the U.S. land area, but in non-lucrative territories. Their survival and profitability was more difficult, not least also because they needed inter-connection services from the AT\& T-owned Bell Operating Companies. Since 1984 Bell Operating Companies have had a large part of their monopoly-rights taken away, and their operations are under far greater scrutiny. There has been a major transformation in their environments, with inconsistent changes in intra-firm psychological dimensions which are very strong.

The results, as can be observed, are very interesting. The average revenue maximization score for the Bell companies was higher in the period 1978 to 1981. As explained, they have historically had the prime urban locations as their franchises, and have exploited their erstwhile monopoly positions in these. Conversely, in the period to the end of 1981, that is for the years 1973, 1978 and 1981, the average cost minimization scores for the non-Bell companies were significantly higher compared to the Bell companies. What does this evidence imply? It seems that the Bell companies, which had relatively greater monopoly power, used such factors to their advantage in being more aggressive in revenue capture as opportunities opened from 1978. At the same time they displayed the classic symptoms of monopoly in that they were less efficient than their counterpart (non-Bell) firms who did not have the AT \& T monopoly privileges and had to struggle more to ensure acceptable performance.

However, following the divestiture of 1984 , the data reveal interesting dynamics at work. With divestiture the Bell companies were reconstituted into seven regional operating company groups. However, the other independents still retained their existing structures, carrying with them the burden of history and path-dependencies, and did not face the same "divestiture shock" as the Bell companies. A comparison of the different scores for 1981 and 1987 reveals the following trends. From reviewing the revenuc maximization score we note that the Bell companics scemed to bc losing their strong edge in being more x-efficient than the non-Bell companies in revenue maximization, perhaps as a result of implementing the 1984 divestiture order, but have subsequently caught up. 
Where, however, the cost minimization score is concerned the story is different; the Bell companies have certainly now caught up. Not only are they no longer more inefficient than the non-Bells, they are indeed equal or better performers. Reviewing Table 6, we note that in 1984 the Bell companies' average cost minimization scores are on average significantly greater than those for the non-Bells, while in the following period, 1987, they are higher than that of the non-Bell companies, though not significantly so. It is possible that the major strategic change brought about by the 1984 divestiture enabled the Bell companies to "wipe the slate clean" and start with fresh behavioral predilections. Conversely, the non-Bell independents still seem to be caught up with history and path dependencies. Hence, the display of relatively unremarkable patterns of improvement in their performance when compared to the Bell companies.

\section{Summary}

We have demonstrated a psychology-based framework that is useful in explaining dynamic performance changes of firms that occur as a result of market liberalization. The underlying postulates of $x$-efficiency theory provide a useful anchor in this endeavor. We illustrate the framework with reference to firms in the U.S. telecommunications industry. A brief summary of our results yields the information that in the period 1973 to 1987 firms in the telecommunications industry have significantly improved their relative micro-micro performance. X-efficiencies seem to have been released by market liberalization, and these have led to both revenue augmentation and input conservation over the fifteen-year period that we study; we do, however, find a greater consistency over time in the pattern of improvement in the cost minimization score. Thus there may be several other forces at play which can have a major impact on scores, and a decomposition of these scores via regression analysis may reveal the influence of many factors. These factors are translated into operational outcomes through various actions within firms, such as changing reporting relationships, technology adoption and rationalization of activities which make work easier.

DEA enables us to identify how each firm fares relative to the other members of its cohort, and for conducting detailed micro-micro analysis such information can aid decision-makers in drawing inferences about the output augmentation or resource conservation strategies that need to be 
undertaken if firms want to attain a position on the frontier. Because we have postulated that with emerging liberalization of their environments firms will improve their performance as a result of changing behavioral factors within firms, it is necessary to have measures of relative performance between non-liberalized and liberalized periods. Such measures should be able to factor in empirically the impact of such changing firm level behavior within firms. The use of DEA enables such measures to be developed, and, consequently, the precise impact of public or business policies on the direction of performance outcomes of firms can be assessed.

\section{Acknowledgment}

I am grateful to two anonymous referees for their comments which have substantially improved the paper.

\section{References}

Babilot, G., R. Frantz and L. Green, 1987. Natural monopolies and rent: A Georgist remedy for $\mathrm{x}$-inefficiency among publicly regulated firms. American Journal of Economics and Sociology 46, 2 , $205-217$.

Banker, R.D., A. Charnes and W.W. Cooper, 1984. Some models for estimating technical and scale efficiencies in data envelopment analysis. Management Science 30, 1078-1092.

Bauer, P.W., 1990. Recent developments in the econometric estimation of frontiers. Journal of Econometrics 46, 39-56.

Baumol, W.J., J.C. Panzar and R.D. Willig, 1982. Contestable Markets and the Theory of Industrial Structure. New York: Harcourt, Brace, Jovanovich.

Bolter, W., J. McConnaughey and F. Kelsey, 1990. Telecommunications Policy for the 1990's and Beyond. Armonk, NY: M.E. Sharpe.

Bureau of the Census. Annual Statistical abstract of the United States. Washington, DC: U.S. Department of Commerce.

Button, K.J. and T.G. Weyman-Jones, 1992. Ownership structure, institutional, organizational and measured x-efficiency. American Economic Review 82, 439-445.

Charnes, A., W.W. Cooper and E. Rhodes, 1978. Measuring the efficiency of decision making units. European Journal of Operations Research 2, 429-444.

Comanor, W.S. and H. Leibenstein, 1969. Allocative efficiency, x-efficiency and the measurement of welfare Josses. Economica 15, 304-309.

Crandall, R.W., 1991. After the breakup: U.S. Telecommunications in a More Competitive Era. Washington, DC: The Brookings Institution.

Dovring, F., 1979. Underemployment, slow motion and $\mathrm{x}$-cfficiency. Economic Development and Cultural Change 21, 485-490.

Farrell, M.J., 1957. The measurement of productive efficiency. Journal of the Royal Statistical Society (Series A (General)), 120, Part 3, 253-281.

Hayek, F.A., 1945. The use of knowledge in society. American Economic Review 35, 519-530. 
Hoenack, S.A., 1989. Group behavior and economic growth. Social Science Quarterly 70, 759-764.

Langdale, J., 1983. Competition in the U.S. long-distance telecommunications industry. Regional Studies 17, 393-409.

Leibenstein, H., 1976. Beyond Economic Man. Cambridge, MA: Harvard University Press.

Leibenstein, H., 1987. Inside the Firm: The Inefficiencies of Hierarchy. Cambridge, MA: Harvard University Press.

Leibenstein, H. and S. Maital, 1992. Empirical estimation and partioning of $\mathrm{x}$-inefficiency: A data-envelopment approach. American Economic Review 82, 428-433.

Majumdar, S.K, 1994. Assessing firms' capabilities: Theory and measurement. Economic and Political Weekly 29, M83-M89.

Mann, H.B. and D.R. Whitney, 1947. On a test of whether one of two random variables is stochastically larger than the others. The Annals of Mathematical Statistics 18, 50-60.

McCain, R.A., 1975. Competition, information, redundancy: X-efficiency and the cybernetics of the firm. Kyklos 28, 286-308.

McClelland, D.C. and D.G. Winter, 1969. Motivating Economic Achievement. New York: The Free Press.

McNulty, P., 1968. Economic theory and the meaning of competition. Quarterly Journal of Economics $82,639-656$.

Meyer, J.R., R.W. Wilson, M.A. Baughcum, E. Burton and L. Caouette, 1980. The Economics of Competition in the Telecommunications Industry. Cambridge, MA: Oelgeschlager, Gunn and Hain, Publishers.

Nelson, R.R., 1991. Why do firms differ, and how does it matter. Strategic Management Journal, Summer Special Issue, 61-74.

Seiford, L.W. and R.M. Thrall, 1990. Recent development in DEA: The mathematical programming approach to frontier analysis. Journal of Econometrics 46, 7-38.

Shelton, J., 1967. Allocative efficiency versus x-efficiency: Comment. American Economic Review 57, $1252-1258$.

Shen, T.Y., 1991. Towards a general theory of $x$-efficiency. Journal of Socio-Economics 20, 277-295.

Shepherd, W.G., 1983. 'Concepts of competition and efficient policy in the telecommunications sector'. In: E.M. Noam (Ed.), Telecommunication Regulation: Today and Tomorrow. New York: Harcourt, Brace, Jovanovich.

Smith, A., 1776/1937. An Inquiry into the Nature and Causes of the Wealth of Nations. New York: Modern Library.

Statistics of Communications Common Carriers. (Annual) Washington, DC: Federal Communications Commission.

Stigler, G., 1976. The x-istence of x-efficiency. American Economic Review 66, 213-216.

Tanner, W. and J. Swets, 1954. A decision-making theory of visual detection. Psychological Review 61, 401-409.

Weisman, D.L., 1988. Default capacity tariffs: Smoothing the transitional regulatory asymmetries in telecommunications markets. Yale Journal of Regulation 5, 149-178.

Wilcoxon, F., 1945. Individual comparisons by ranking methods. Biometrics 1, 80-83. 